\title{
Complex communication
}

\author{
In the world of Web 2.0, the variety of channels for communicating science is exploding. Technology can help \\ to generate images that attract attention, but there is much more to reaching the public than pretty pictures.
}

Science communication will never be the same again. The traditional path of scientific discoveries from bench to breakfast table - through scientific journals and newspapers - is diversifying at a staggering rate. Blogs by scientists and non-scientists alike are jostling for public attention; research institutions provide websites, films and press releases; and scientific information is 'Flickring' and 'Twittering' away in Web 2.0, accessible to anyone who is interested.

Given this variety of competition, researchers work hard to make their work stand out from the crowd. A session at the General Assembly of the European Geophysical Union (EGU) in April - entitled 'The Significance of Marine Technology in Science Communication Challenges and Opportunities' - highlighted an increasingly important selling point for science in the public arena: the volume of publicity that can be generated by stunning images.

Planetary scientists have long exploited the power of unique pictures that capture the attention of researchers and the public alike. The Cassini/Huygens mission to the Saturn system led to a veritable Titan-fever among amateurs, not least because all images were immediately posted on a freely accessible website. The computer-literate enthusiasts even outcompeted the space agencies when it came to producing animations of the surface of Saturn's moon (Nature doi:10.1038/ news050117-7; 2005).

Stimulating the imagination of the next generation of potential scientists with beautiful or intriguing pictures should be applauded. Many a good scientist has been drawn into his or her field by an early fascination with its imagery. And as public funding bodies require tangible societal

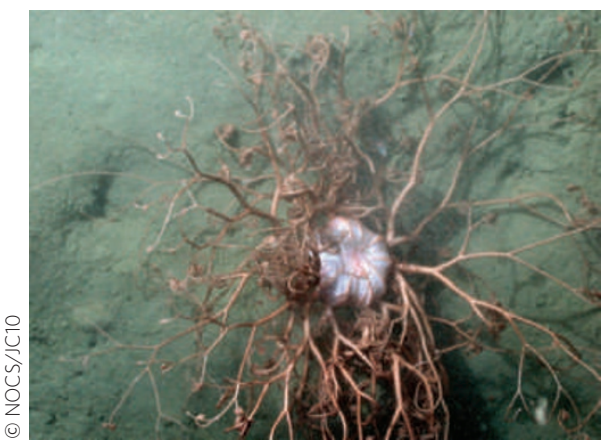

benefits in return for their generosity, widespread interest in a research project is a welcome boost for the next proposal.

Presentations at the EGU session made it clear that marine researchers have now caught on. Remotely operated vehicles that delve into the deep ocean deliver fascinating photographs and films from a world where no human has ever set foot. The footage of bizarre deep-sea creatures and ancient shipwrecks is lapped up by journalists, who know that images sell stories. Now public attention is being bestowed on deep-sea research - a field not previously known for its success with the general public.

Yet photographs gained through technological advances are usually transmitted to the public through stakeholders. The aim of any press office is to gain as much attention as possible for their research institution. Media outreach personnel are not employed to be disinterested chroniclers of scientific progress, but to push the findings of the scientists at their university or lab to the top of the news agenda.

As the science sections in quality newspapers are shrinking, press offices are being expanded (Nature 458, 274-277; 2009). If this trend continues, reporters will have less time to research their stories, but more (and better) press releases to work from. As a result, general readers who want to keep up with scientific progress may no longer be able to rely on their morning paper to deliver a fair overview of the best research (as opposed to the work done at the institutions with the most efficient press offices). Already at least, young science enthusiasts prefer to seek out their sources from an almost infinite online choice, rather than from a limited number of newspapers delivering the same news package to all their readers.

But unlimited choice is not always a good thing. In a world where everyone solicits their own sources of information, it will be much harder to find a common basis for discussion within society. It is difficult for someone outside a field to judge which blog provides a level-headed assessment, and which distorts the facts to fit an agenda. Furthermore, there is the danger that people will choose to build support for their prejudices and preconceived ideas, rather than allowing a trusted newspaper to challenge their established patterns of thinking.

The difficulty lies with communicating the more complicated aspects of science to more than a niche of dedicated followers. Explaining progress in the context of earlier work requires background knowledge and research, as does writing about the uncertainties, contradictions and pitfalls that are an integral part of science. To provide a fair overview of the wealth of published papers requires a disinterested observer.

Researchers' blogs can provide a valuable insider perspective on the progress of science. Press officers can (and should) bring the work of the scientists they represent to the attention of the media, and stunning images are an excellent means of achieving this goal. But it takes someone outside the research institutions to assemble all the available information into a coherent picture.

As the advertising-based business model of the print media is crumbling in the face of cheaper offers online, the need for fulltime science reporters (writing online or in print) remains. A society in which science and technology are central must provide the funding to bring the narrative of scientific progress to the public.
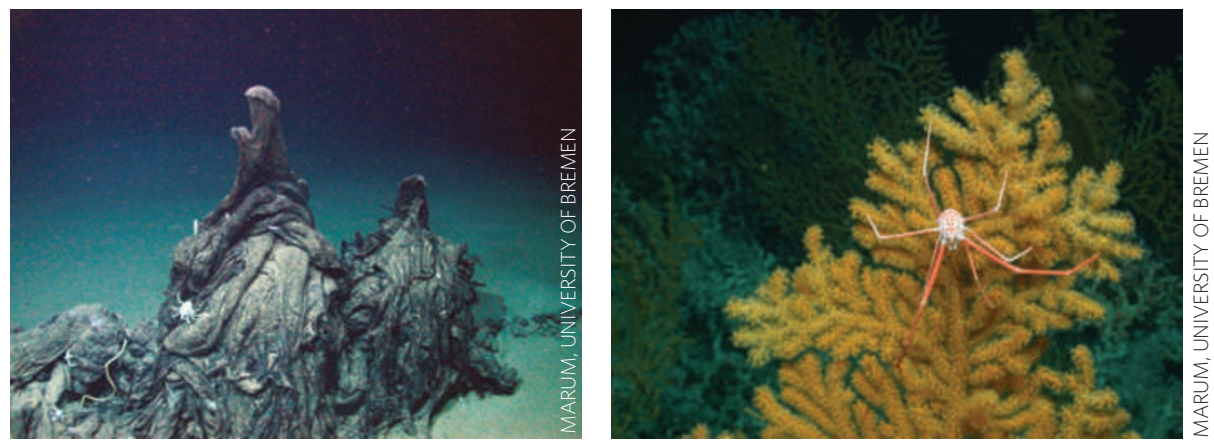